\title{
Dialkyldithiophosphate Acids (HDDPs) as Effective Lubricants of Sol-Gel Titania Coatings in Technical Dry Friction Conditions
}

\author{
Ireneusz Piwoński • Aneta Kisielewska
}

Received: 18 November 2009/Accepted: 21 October 2011/Published online: 12 November 2011

(C) The Author(s) 2011. This article is published with open access at Springerlink.com

\begin{abstract}
The goal of this study was the investigation of the effectiveness of dialkyldithiophosphate acids (HDDPs) films in improving the tribological properties of thin, solgel derived titania coatings. Amorphous, anatase, and rutile titania coatings were obtained using sol-gel dip-coating deposition after treatment at 100,500 , and $1,000{ }^{\circ} \mathrm{C}$, respectively. Titania coatings were then modified from the liquid phase by HDDPs acids having dodecyl- $\left(\mathrm{C}_{12}\right)$, tetradecyl- $\left(\mathrm{C}_{14}\right)$, and hexadecyl- $\left(\mathrm{C}_{16}\right)$ alkyl chains deposited by dip-coating (DC) and Langmuir-Blodgett (LB) methods. The influence of the deposition procedure, the length of the HDDPs alkyl chain and the type of titania substrate on the surface morphology and tribological properties were studied. It was found, using wetting contact angle measurements, that these modifications of titania coatings decrease the surface free energy and increase its hydrophobicity. The surface topography imaged by Atomic force microscopy (AFM), exhibit island-like or agglomerate features for the DC deposition method, while smooth topographies were observed for LB depositions. Tribological tests were conducted by means of a microtribometer operating in the normal load range $30-100 \mathrm{mN}$. An enhancement of tribological properties was observed upon modification, as compared to unmodified titania.
\end{abstract}

Keywords Antiwear additives - Nanotribology · Titanium oxides $\cdot$ AFM $\cdot$ Surface energy

I. Piwoński $(\bowtie) \cdot$ A. Kisielewska

Department of Materials Technology and Chemistry, University

of Lodz, Pomorska 163, 90-236 Lodz, Poland

e-mail: irek@uni.lodz.pl

\section{Introduction}

The literature available today provides a large number of applications for zinc dialkyldithiophosphate (ZDDP) as effective AW/EP additives lowering friction and reducing wear in various frictional configurations (steel-steel, steelceramics, ceramics-ceramics) [1-9]. Good tribological performance results from the possibility of the strong adsorption of ZDDP molecules on surfaces of the elements of devices under friction. As well, products of decomposition of ZDDP may be strongly adhered to the substrate forming tribofilm, which additionally protects the surface. It seems that an even more effective solution would be the application of dialkyldithiophosphate acids (HDDP) because of their stronger affinity to the surface due to the formation of chemical bonds with a substrate. In such systems more energy is required to remove chemisorbed molecules from the surface and hence such a layer better protects the surface from the wear.

Chen et al. [10] modified sol-gel derived $\mathrm{TiO}_{2}$ coatings using the following phosphoric acid esters: di-(2-ethylhexyl) phosphate, $n$-dodecyl phosphoric acid ester, $n$-hexadecyl phosphoric acid ester, and $n$-octadecyl phosphoric acid ester. The formation of self-assembled alkane phosphate monolayers caused a significant increase of the water wetting contact angle exceeding $90^{\circ}$ after $6 \mathrm{~h}$ of selfassembling. Maximal values of water wetting contact angles $\left(100-104^{\circ}\right)$ were obtained after $24 \mathrm{~h}$ of selfassembly. XPS analysis revealed that titanium atoms on the $\mathrm{TiO}_{2}$ surface were chelated by the phosphate headgroup via intermolecular hydrogen bonding creating mono-, bi-, and tridentate coordinations. It was also found that an increase of the chain length in monoalkanephosphates decreased the coordination ratio monodentate/bidentate giving better stability and a higher degree of order of the long-chain 
monoalkane phosphate SAMs (self-assembled monolayers). Coefficients of friction recorded at the macro scale at $0.5 \mathrm{~N}$ normal load exhibited lower values for longer alkyl chains.

Hofer et al. [11] investigated self-assembled monolayers of dodecyl phosphates and 12-hydroxy dodecyl phosphates on thin layers of $\mathrm{Al}_{2} \mathrm{O}_{3}, \mathrm{Ta}_{2} \mathrm{O}_{5}, \mathrm{Nb}_{2} \mathrm{O}_{5}, \mathrm{ZrO}_{2}$, and $\mathrm{TiO}_{2}$ deposited on the glass substrate. The self-assembly process was carried out for $48 \mathrm{~h}$. Deposited monolayers of alkyl phosphates on transition-metal oxides as well as on aluminum oxide exhibited high level of hydrophobicitythe wetting contact angle for water was $110-115^{\circ}$.

In contrast to other oxides, the wetting contact angle for water measured on a silicon dioxide substrate was only $10^{\circ}$ indicating that no alkyl phosphates were present at the surface. It means that the creation of alkyl phosphate layers from water solutions in the case of silicon dioxide is limited due to the lower affinity of alkyl phosphates to Si(IV) in contrast to $\mathrm{Al}(\mathrm{III}), \mathrm{Ti}(\mathrm{IV}), \mathrm{Nb}(\mathrm{V})$, and $\mathrm{Ta}(\mathrm{V})[12,13]$, which are well-known as metals forming strong coordinative complexes with phosphates.

The physicochemical properties of the surface may also be altered by other methods of modification. Marguerettaz and Fitzmaurice [14] prepared monolayers of aliphatic eicosylcarboxylic (RC) and eicosylphosphonic (RP) acids using the LB method. Silver, gold, conducting glass doped with tin oxide, and nanostructured semiconducting titanium dioxide, were used as substrates. It was calculated that in case of RC acid one molecule covers $23 \AA^{2}$ and in case of RP acid one molecule covers 20-23 $\AA^{2}$ depending on pH and the addition of $\mathrm{Cd}^{2+}$ ions. Both calculations refer to the titanium dioxide substrate. Investigations demonstrated great technological potential for improving nanocrystalline photovoltaic cells and electrochromic effects based on titanium dioxide, where deposited molecules play the role of linker groups. The above-mentioned reports provide valuable data concerning the tribological and physicochemical properties of alkyl phosphate/phosphonate derivatives deposited on titanium dioxide using the LB technique or self-assembling methods. Previous studies about the application of ZDDP compounds in the lubrication of titanium dioxide coatings as well as reports from other scientific groups encouraged us to use HDDPs for further investigation. These types of modifier have similar structures to ZDDP, but contrary to ZDDP contain reactive -SH group which enhances interactions between modifier and titania surface.

Titanium dioxide, excluding Magneli phases, is not often applied as a tribological coating. However, the wide range of applications for $\mathrm{TiO}_{2}$ in the form of thin films in optical, microelectronic, photoelectronic devices, and anticorrosion coatings need an enhancement of the selfprotection of these coatings from scratching and wear. In this context, less research about tribological properties of titania films is available today.

Since coatings are prepared by sol-gel methods an additional thermal process is required to get crystalline phases of titania. Travers [15] determined the temperature formation of anatase to be about $350{ }^{\circ} \mathrm{C}$ while pure rutile was observed above $900{ }^{\circ} \mathrm{C}$. Hirashima [16] did not observe the presence of anatase after annealing at $300{ }^{\circ} \mathrm{C}$. It appeared only after annealing the coating at $500{ }^{\circ} \mathrm{C}$ for $1 \mathrm{~h}$. The most suitable annealing temperatures to obtain anatase and rutile are 500 and $1,000{ }^{\circ} \mathrm{C}$, respectively.

The Langmuir-Blodgett and dip-coating methods were selected as the deposition techniques of HDDP. The LB techniques allow monolayers of HDDP to be obtained whereas in the DC method, dense coatings can be prepared. The thickness can be controlled by the concentration of HDDP in the solution, the rate of the substrate immersion/ withdrawal and by the volatility of solvent.

The aim of this study was to present an effective method of improving tribological properties of titania coatings working under technical dry friction condition in the miliNewton load range by modification of its surface by HDDPs. The effect of the annealing temperature of titania, alkyl chains length $\left(\mathrm{C}_{12}, \mathrm{C}_{14}, \mathrm{C}_{16}\right)$ of HDDP and the deposition method (LB and DC) on the lowering of the friction coefficient and wear were studied during the sliding of ceramic surfaces in the presence and without HDDP.

\section{Experimental}

\subsection{Materials and Chemicals}

Dialkyldithiophosphate acids (HS-PS(OR) $)_{2} ; \mathrm{R}=\mathrm{C}_{12}, \mathrm{C}_{14}$, $\mathrm{C}_{16}$ ) were synthesized in our laboratory according to method described in [17]. The quality of the final products was confirmed by ${ }^{31} \mathrm{P}-\mathrm{NMR}$. One peak in the range of 85-87 ppm was observed depending on sample, which is different from the signal coming from ZDDP salts (96-99 ppm). The HDDP structure was also compared with the structure of ZDDP by infrared spectroscopy-Fig. 1 . Both spectra exhibit practically the same signals, except two bands visible in acid spectra at 2453 and $874 \mathrm{~cm}^{-1}$, which correspond to the stretching and deformation vibrations of $\mathrm{S}-\mathrm{H}$ bond, respectively. These signals are present only in the spectra recorded for acid. Besides, both spectra are practically the same and exhibit typical for dithiophosphates absorption bands: $\mathrm{P}-\mathrm{O}-\mathrm{C} \sim 1,000 \mathrm{~cm}^{-1}$ (doublet); $\mathrm{P}=\mathrm{S} 650 \mathrm{~cm}^{-1}$; $\mathrm{P}-\mathrm{S} 670 \mathrm{~cm}^{-1}$ [18].

$\mathrm{Si}(100)$ wafers polished on one side were obtained from Cemat Silicon S.A., Warsaw, Poland. Titanium(IV) isopropoxide $98 \%$ was obtained from ABCR GmbH and Co. KG Karlsruhe, Germany; Anhydrous ethyl alcohol 99.8\%, 
Fig. 1 FT-IR spectra of zinc dialkyldithiophosphate (ZDDP) and dialkyldithiophosphate acid (HDDP)

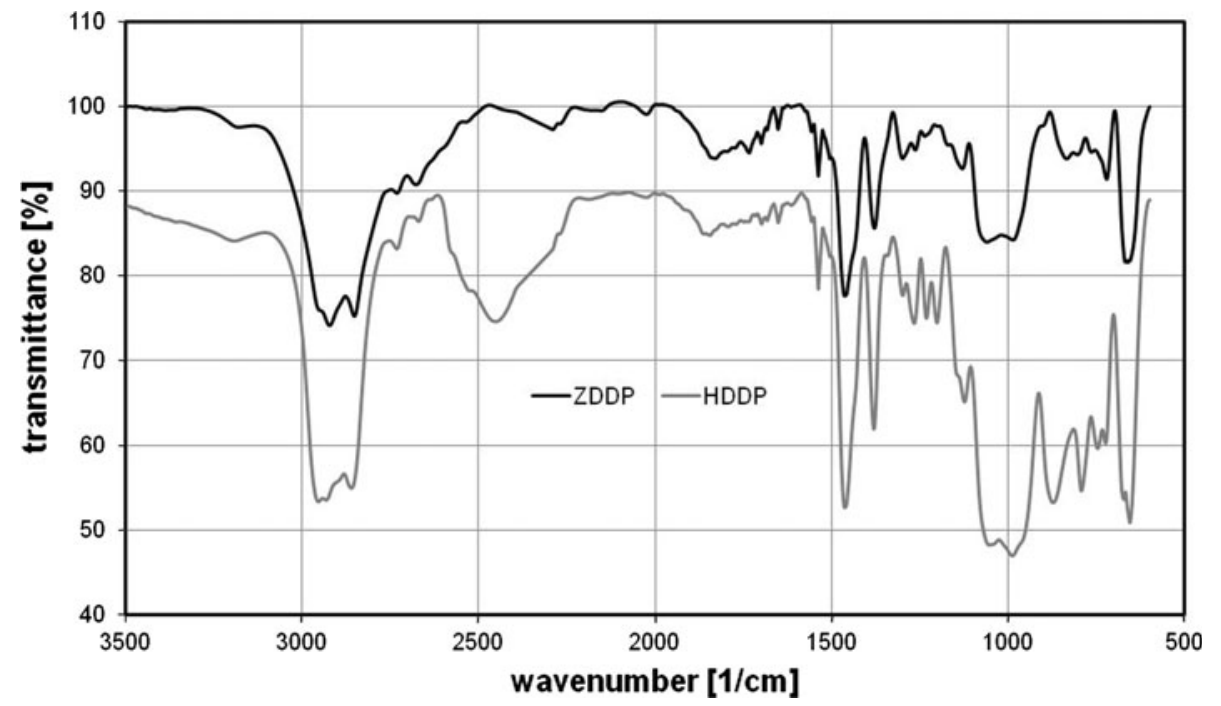

was obtained from Eurochem BGD Ltd.-Tarnów, Poland; and 2-propanol, 99.5\%, was obtained from POCh, Gliwice, Poland.

\subsection{Sample Preparation}

Thin titanium dioxide layers were prepared on $\mathrm{Si}(100)$ wafers using the sol-gel dip-coating method described in detail in our previous reports $[19,20]$. Silicon wafers were used as received, without any further pretreatment. After deposition, the titanium dioxide layers were thermally treated at $100{ }^{\circ} \mathrm{C}$. These samples were labeled as "as made". In order to get anatase and rutile phases "as made" coatings were heated at 500 and $1,000{ }^{\circ} \mathrm{C}$, respectively. Titania coatings prepared in this way were used as substrates for further deposition of HDDP organic films.

Three types of HDDPs were used as titania surface modifiers: di(n-dodecyl)dithiophosphate acid ( $\left.\mathrm{C}_{12} \mathrm{HDDP}\right)$, $\operatorname{di}\left(n\right.$-tetradecyl)dithiophosphate acid $\left(\mathrm{C}_{14} \mathrm{HDDP}\right)$, and di( $n$-hexadecyl)dithiophosphate acid $\left(\mathrm{C}_{16} \mathrm{HDDP}\right)$.

Modifiers were deposited on titanium dioxide substrates (TDS) by: DC and LB methods.

Dip-coating procedure consisted of immersion of appropriate TDS in $1 \mathrm{wt} \%$ solution of HDDP in ethanol with a constant immersion and withdrawal rate of $25 \mathrm{~mm} \mathrm{~min}{ }^{-1}$.

For the purpose of LB deposition three solutions having the concentration of $1.5,1.7,1.9 \mathrm{mg} \mathrm{ml}^{-1}$ of $\mathrm{C}_{12} \mathrm{HDDP}$, $\mathrm{C}_{14} \mathrm{HDDP}$, and $\mathrm{C}_{16} \mathrm{HDDP}$ were prepared in chloroform. These concentrations correspond to the molar concentration of arachidic acid used as reference compound recommended by LB apparatus manufacturer (NIMA Technologies). Solutions of HDDPs were introduced to the water-air interface in apparatus trough using the $5 \mu 1$ syringe by injection of $9 \mu \mathrm{l}$ solution of $\mathrm{C}_{12} \mathrm{HDDP}$ and $8 \mu \mathrm{l}$

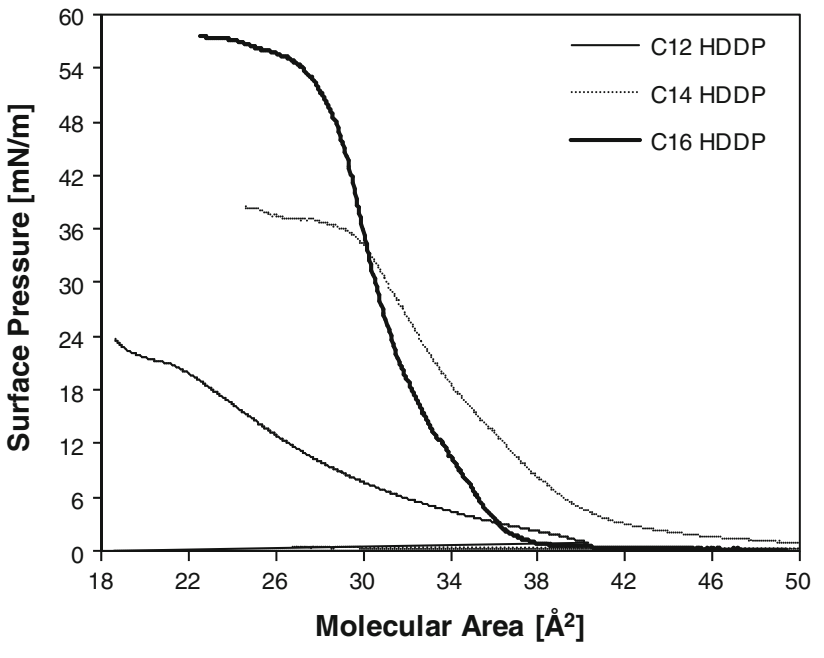

Fig. 2 Surface pressure versus molecular area isotherms for HDDP $\mathrm{C}_{12}, \mathrm{C}_{14}$, and $\mathrm{C}_{16}$

solution of $\mathrm{C}_{14}$ and $\mathrm{C}_{16}$ HDDPs. In the next step pressure versus area isotherms were recorded. Correct isotherms were obtained in repeatable manner for all investigated modifiers. The surface pressure versus molecular area isotherms for $\mathrm{C}_{12}, \mathrm{C}_{14}$, and $\mathrm{C}_{16}$ HDDPs are presented in Fig. 2. On the basis of the obtained isotherms, deposition pressures of $18,32,50 \mathrm{mN} \mathrm{m}^{-1}$ were chosen for $\mathrm{C}_{12}, \mathrm{C}_{14}$, and $\mathrm{C}_{16}$ alkyl chains, respectively.

\subsection{Atomic Force Microscopy Surface Imaging}

The surface topography was imaged in tapping mode with the use of a NT-MDT microscope equipped in a Smena head operating under ambient conditions in air. Silicon cantilevers from Budget Sensors BS-Tap 300 Al having a quoted force constant $k=40 \mathrm{~N} \mathrm{~m}^{-1}$ and resonance frequency $v=241 \mathrm{kHz}$ were used. Typical scan size of 
the image was fixed at $5 \mu \mathrm{m} \times 5 \mu \mathrm{m}$ for the surface topography.

\subsection{Contact Angle and Surface Free Energy Measurements}

The contact angle measurements were performed by the sessile drop technique. The surface free energies of TDS and the substrates modified by HDDP acids were calculated using the Van Oss-Chaudhury-Good method. Details about this method may be found elsewhere [21, 22]. The drop of liquid (water, glycerine and diiodomethane) was deposited on the substrate with the use of a micro-syringe. Droplets were observed by a digital camera connected to a computer equipped with the software (Motic Images Plus 2.0) thus enabling the measurement of the contact angle.

\subsection{Frictional Measurements}

Frictional measurements were performed with the use of a microtribometer operating under ambient temperature in air. All measurements were recorded with the following parameters:

- normal load range: $30-100 \mathrm{mN}$

- counterbody: YSZ (ytria-stabilized zirconia ball, diameter $5 \mathrm{~mm}$ )

- frictional distance (length of the single track): $5 \mathrm{~mm}$

- velocity: $25 \mathrm{~mm} \mathrm{min.}{ }^{-1}$

- technical dry friction conditions

\subsection{AFM Frictional Measurements}

Atomic force microscopy frictional measurements were performed with the use of a NT-MDT microscope equipped with a Smena head operating in contact mode under ambient conditions in air. NSC silicon rectangular cantilever covered by $\mathrm{Si}_{3} \mathrm{~N}_{4}$ manufactured by MikroMasch, having force constant $k=4.5 \mathrm{~N} \mathrm{~m}^{-1}$ and resonance frequency $v=142.1 \mathrm{kHz}$ was used. The scan size was fixed at $5 \mu \mathrm{m} \times 5 \mu \mathrm{m}$. The surface was scanned once upwards and once downwards in the same place at a scanning rate of $1 \mathrm{~Hz}$. The cantilever was not calibrated and therefore the recorded data were comparative. Calibration of the cantilever is quite sophisticated due to the large error of normal and lateral spring constants. Moreover, determination of absolute values of normal and lateral forces is limited due to the presence of other forces difficult to estimate in ambient conditions like Van der Waals, electrostatic, and capillary forces. However, keeping identical microscope settings, using the same cantilever under the same environmental conditions and performing the measurement in a reasonably short time, relative changes in friction between samples may be determined quite accurately. The distance between branches in frictional loops obtained during scanning the tip forward and backwards over the surface in contact mode was calculated as total friction. These distances were compared for all samples.

\subsection{Optical Microscopy Measurements}

An optical microscope operating at the magnification of $80 \times$ was used for the assessment of the wear traces after frictional tests. For the purpose of this study the maximum width of the each individual wear track was measured and used in further data processing, as the wear parameter.

\section{Results and Discussion}

\subsection{Surface Morphology}

Atomic force microscopy images of titania substrates and HDDP films deposited on TDS using the DC and LB methods are presented in Fig. 3. AFM images show the topography of homogenous titania coatings without any defects, however, the roughness of the titania films depend on the temperature of annealing. Samples heated at $100{ }^{\circ} \mathrm{C}$ are smooth while after treatment at 500 and $1,000{ }^{\circ} \mathrm{C}$ grainy features are visible which is related to the presence of crystalline forms of titania: anatase and rutile, respectively, at these temperatures $[15,16]$. The rms surface roughness of titania coatings oscillates between 0.2 and $1.4 \mathrm{~nm}$. The degree of titania surface hydroxylation was estimated by FT-IR spectroscopy and presented in our previous report concerning the modification of titania surface by fluoroalkylsilanes from vapor phase [20].

After modification with HDDP acids, the surface topography changes depending on the applied type of modifier, the method of deposition and the substrate. Previously investigated and deposited at practically the same parameters on identical titania substrates some of ZDDP films were visible as large agglomerates, due to the wellknown affinity of ZDDP to form dimers and oligomers [23]. In the case of HDDP films fewer agglomerates are visible. This is attributed to the stronger affinity of HDDP to the titania surface and also longer alkyl chain length in the applied HDDP modifiers. The most visible changes in surface topographies were observed for $\mathrm{C}_{16} \mathrm{HDDP}$ especially for DC deposition. $\mathrm{C}_{16} \mathrm{HDDP}$ films deposited by the DC method exhibit multilayer, flat and island-like topographies for all temperatures of titania substrate annealing. The average height between particular layers is $6 \mathrm{~nm}$. Some agglomerates are visible for LB $\mathrm{C}_{12} \mathrm{HDDP}$ on TDS $500{ }^{\circ} \mathrm{C}$, however, their sizes do not exceed $8 \mathrm{~nm}$. 


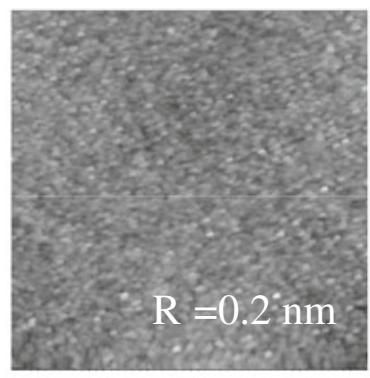

$\mathrm{TiO}_{2} 500{ }^{\circ} \mathrm{C}$

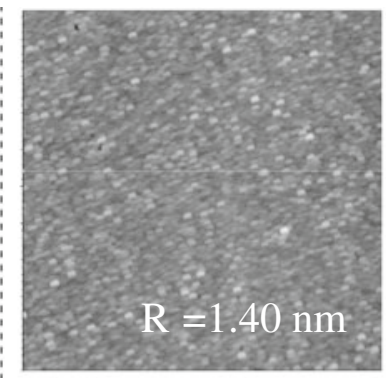

$\mathrm{TiO}_{2} 1000{ }^{\circ} \mathrm{C}$

\section{modifier}
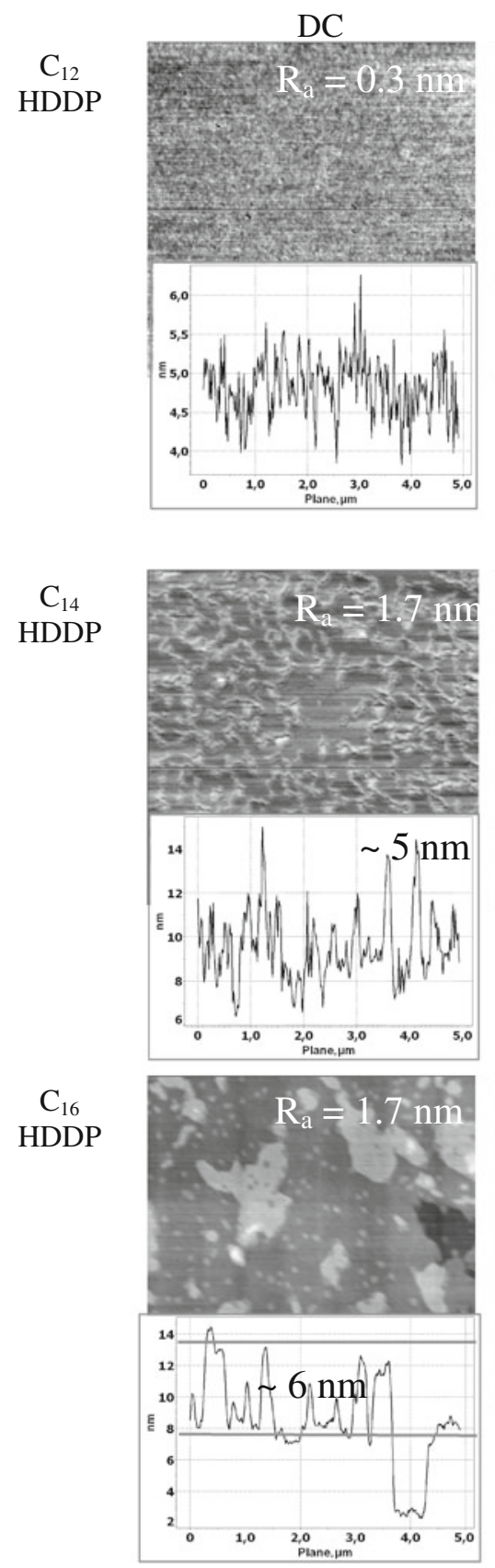

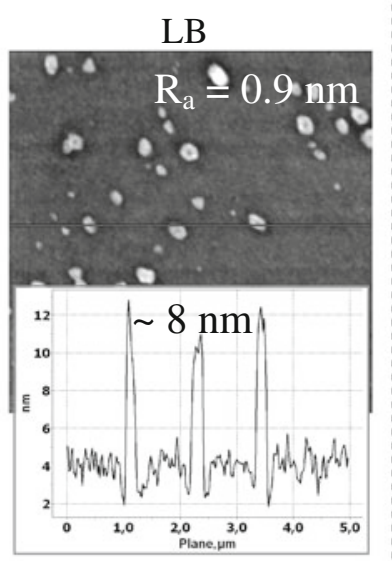

method of modification
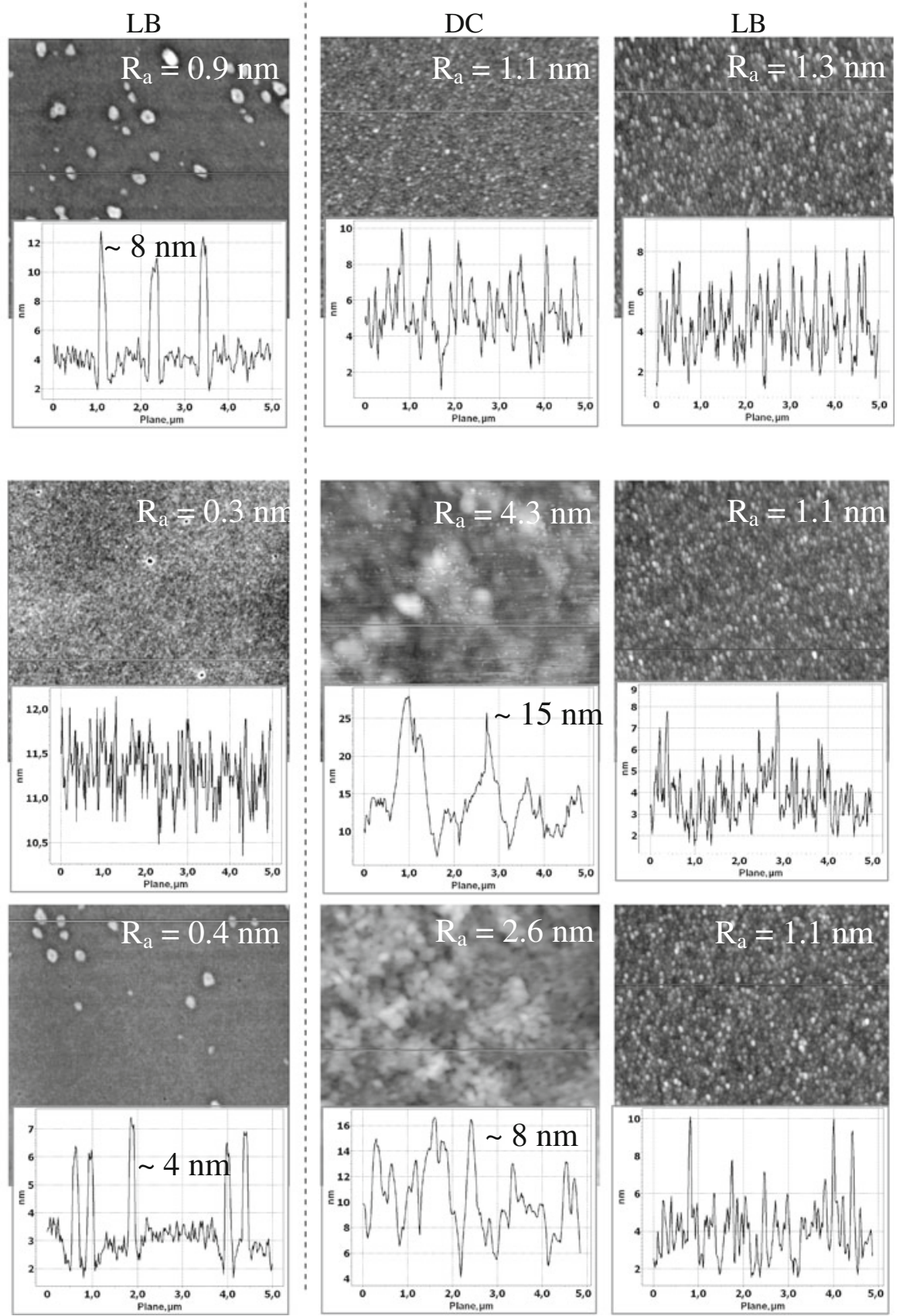

Fig. 3 Atomic force microscopy images $(5 \mu \mathrm{m} \times 5 \mu \mathrm{m})$ of: $\mathrm{TiO}_{2}$ surface annealed at 500 and $1,000{ }^{\circ} \mathrm{C} . \mathrm{C}_{12} \mathrm{HDDP}, \mathrm{C}_{14} \mathrm{HDDP}$, and $\mathrm{C}_{16} \mathrm{HDDP}$ films are deposited by $\mathrm{DC}$ and $\mathrm{LB}$ methods on $\mathrm{TiO}_{2}$ substrates 
Table 1 Wetting contact angels of titania before and after modification and surface free energy components

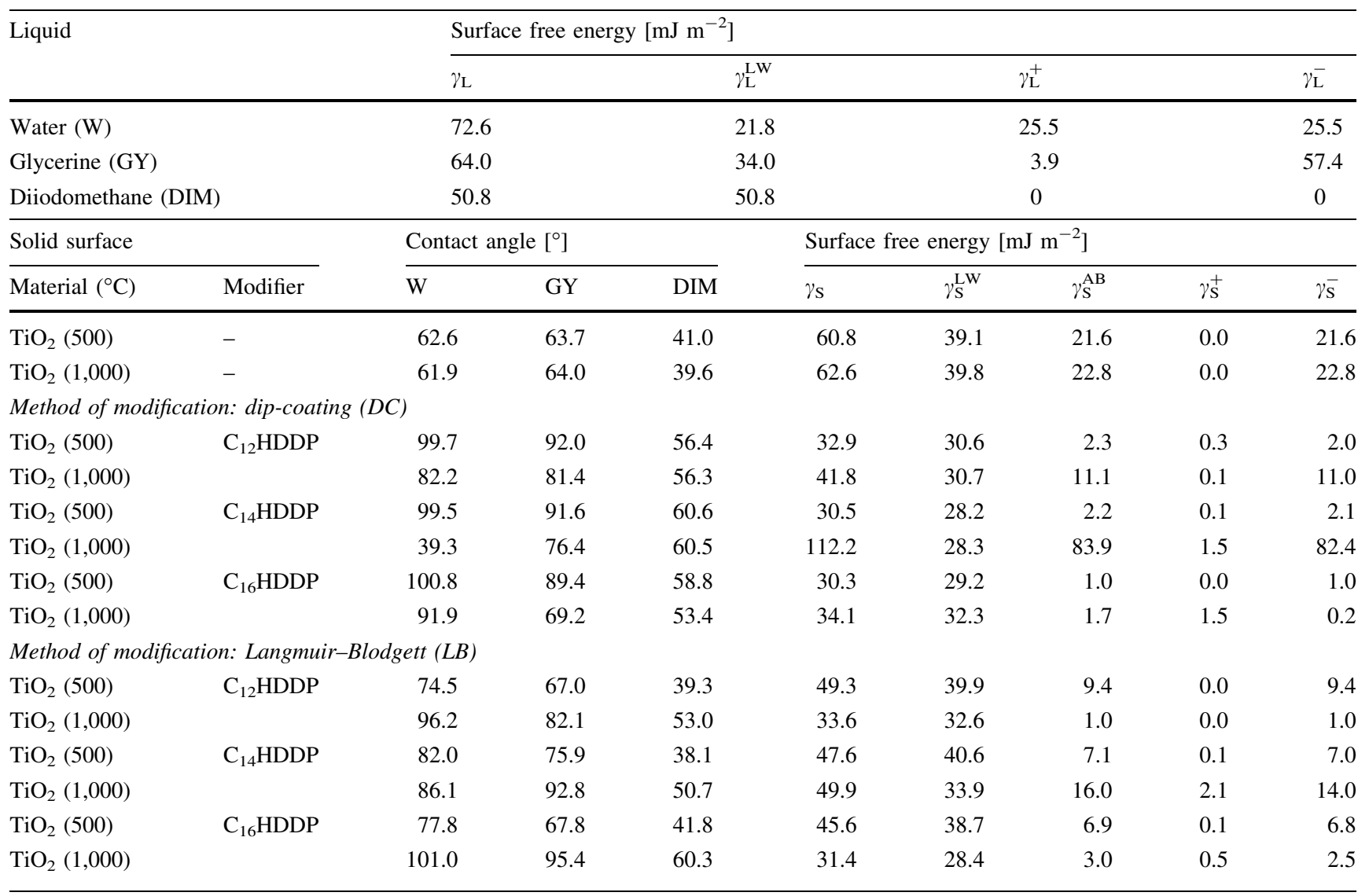

Table 2 Coefficient of friction of titania before and after modification and maximum wear track after frictional test

\begin{tabular}{|c|c|c|c|c|c|}
\hline Material $\left({ }^{\circ} \mathrm{C}\right)$ & Modifier & $\mu$ & $d_{\max }$ & $\mu$ (4 weeks) & $\mathrm{d}_{\max }(4$ weeks $)$ \\
\hline $\mathrm{TiO}_{2}$ as-made & & $0.86 \pm 0.04$ & 55.9 & $0.51 \pm 0.05$ & 46.1 \\
\hline $\mathrm{TiO}_{2} 500$ & & $0.50 \pm 0.03$ & 10.3 & $0.35 \pm 0.02$ & 10.2 \\
\hline $\mathrm{TiO}_{2} 1,000$ & & $0.45 \pm 0.02$ & 2.0 & $0.39 \pm 0.04$ & 5.1 \\
\hline \multicolumn{6}{|c|}{ Method of modification: Dip-coating (DC) } \\
\hline $\mathrm{TiO}_{2} 500$ & $\mathrm{C}_{12} \mathrm{HDDP}$ & $0.18 \pm 0.01$ & - & $0.17 \pm 0.01$ & - \\
\hline $\mathrm{TiO}_{2} 1,000$ & & $0.10 \pm 0.05$ & 1.0 & $0.08 \pm 0.04$ & 1.5 \\
\hline $\mathrm{TiO}_{2} 500$ & $\mathrm{C}_{14} \mathrm{HDDP}$ & $0.10 \pm 0.01$ & - & $0.15 \pm 0.01$ & 3.9 \\
\hline $\mathrm{TiO}_{2} 1,000$ & & $0.05 \pm 0.01$ & - & $0.03 \pm 0.01$ & 1.9 \\
\hline $\mathrm{TiO}_{2} 500$ & $\mathrm{C}_{16} \mathrm{HDDP}$ & $0.13 \pm 0.01$ & 19.0 & $0.14 \pm 0.01$ & 42.8 \\
\hline $\mathrm{TiO}_{2} 1,000$ & & $0.10 \pm 0.01$ & 15.6 & $0.05 \pm 0.01$ & 34.5 \\
\hline \multicolumn{6}{|c|}{ Method of modification: Langmuir-Blodgett (LB) } \\
\hline $\mathrm{TiO}_{2} 500$ & $\mathrm{C}_{12} \mathrm{HDDP}$ & $0.29 \pm 0.02$ & 10.2 & $0.29 \pm 0.02$ & 7.3 \\
\hline $\mathrm{TiO}_{2} 1,000$ & & $0.17 \pm 0.01$ & 2.9 & $0.19 \pm 0.02$ & 2.9 \\
\hline $\mathrm{TiO}_{2} 500$ & $\mathrm{C}_{14} \mathrm{HDDP}$ & $0.37 \pm 0.04$ & 6.8 & $0.25 \pm 0.02$ & 4.4 \\
\hline $\mathrm{TiO}_{2} 1,000$ & & $0.21 \pm 0.01$ & 4.4 & $0.17 \pm 0.01$ & 1.9 \\
\hline $\mathrm{TiO}_{2} 500$ & $\mathrm{C}_{16} \mathrm{HDDP}$ & $0.31 \pm 0.02$ & 10.5 & $0.27 \pm 0.01$ & 6.8 \\
\hline $\mathrm{TiO}_{2} 1,000$ & & $0.20 \pm 0.01$ & 2.9 & $0.24 \pm 0.01$ & 1.5 \\
\hline
\end{tabular}

Less pronounced changes were observed in the case of samples deposited at $1,000{ }^{\circ} \mathrm{C}$ TDS. In this case, the surface roughness influences the topography more than the deposited organic film.
Langmuir-Blodgett deposition results in monolayers of close-packed HDDPs films, which are sometimes accompanied by, as mentioned before, small agglomerates having sizes from $4-8 \mathrm{~nm}$ such as in depositions realized on TDS 

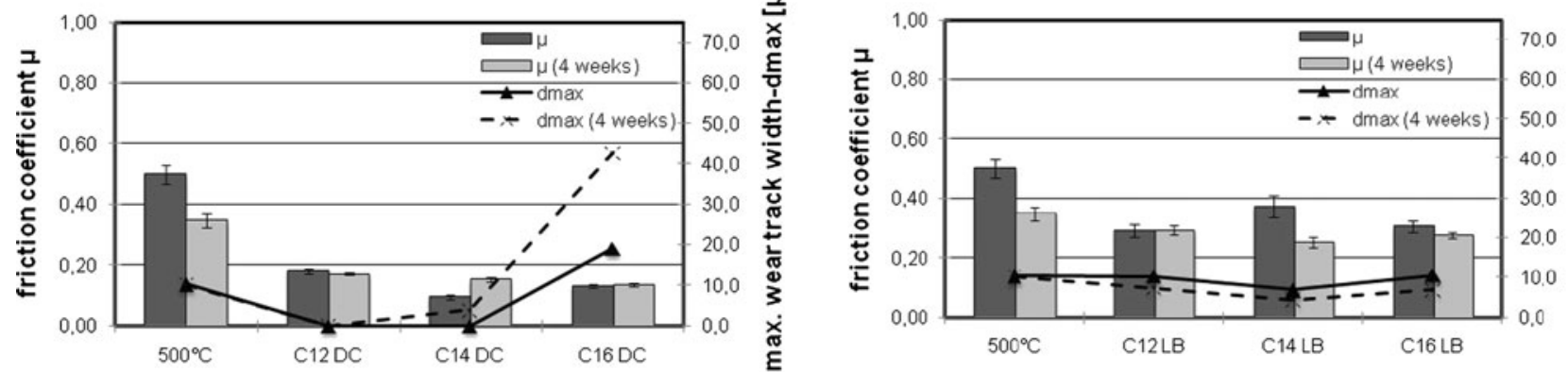

Fig. 4 The effect of the alkyl chains length of HDDP on the frictional properties of titania layers

at $500{ }^{\circ} \mathrm{C}$. Similarly, in ZDDP deposition, high level of surface coverage was achieved also for HDDPs. The transfer ratio was calculated from the shape of the pressure versus area isotherms and the pressure/area versus time graphs. This transfer ratio represents the quotient of area of monolayer removed from subphase at constant pressure to the surface area of substrate immersed in water [24]. It was found that the minimal transfer ratio for all HDDPs was $\geq 98 \%$. The surface roughness of TDS and TDS covered by LB HDDP films is comparable for each annealing temperature.

The pressure versus area isotherms were also used to estimate the surface area occupied by one HDDP molecule. The following values were found: 23,30 , and $28 \AA^{2}$ for $\mathrm{C}_{12}, \mathrm{C}_{14}$, and $\mathrm{C}_{16}$ HDDPs, respectively. It should be highlighted that the parameter which determines the surface area available for one molecule is the value of the deposition surface pressure, which is chosen on the basis of the pressure-area isotherm.

In order to estimate the thickness of LB films, HDDP molecules were also deposited on $\mathrm{Si}$ wafers with identical conditions and surface pressures used during deposition on TDS. Film discontinuities after deposition (small areas uncovered by HDDPs) were analyzed and their depth was considered as the film thickness. It was found that the average film thickness in the case of $\mathrm{C}_{14} \mathrm{HDDP}$ is around $0.6 \mathrm{~nm}$ and for $\mathrm{C}_{16} \mathrm{HDDP}$ is around $1.2 \mathrm{~nm}$.

\subsection{Contact Angle and Surface Free Energy}

In general, wetting contact angles of water for modified TDS are higher than before modification indicating an increase of surface hydrophobicity after modification. In the DC method, high wetting contact angles for water were recorded for anatase, while lower values were observed for rutile. In the case of LB deposition, the lowest water wetting angles were measured for anatase independent of the length of alkyl chain in HDDP.

The same measurements were also performed for glycerin and diiodomethane enabling calculations of the surface free energy. Upon modification, lowering of the surface free energy is observed for all types of TDS, deposition methods, and type of modifier except $\mathrm{C}_{14} \mathrm{HDDP}$ deposited by $\mathrm{DC}$ on $\mathrm{TiO}_{2} 1,000{ }^{\circ} \mathrm{C}$.

In Table 1, the energy components associated with nonspecific dispersion interactions like dipole-dipole and dipole-induced dipole known as Lifshitz-Van der Waals $\left(\gamma_{\mathrm{s}}^{\mathrm{LW}}\right)$ interactions, acid-base $\left(\gamma_{\mathrm{s}}^{\mathrm{AB}}\right)$ interactions as well as components related to Lewis-acid, Lewis-base donor $\left(\gamma_{\mathrm{i}}^{-}\right)$and acceptor $\left(\gamma_{\mathrm{i}}^{+}\right)$interactions are summarized. HDDP-modified TDS samples exhibit higher values of Lifshitz-Van der Waals $\left(\gamma_{\mathrm{s}}^{\mathrm{LW}}\right)$ interactions than acid-base interactions $\left(\gamma_{\mathrm{s}}^{\mathrm{AB}}\right)$. As well, considerably lower acid-base interactions for HDDP films were observed as compared to unmodified TDS. 

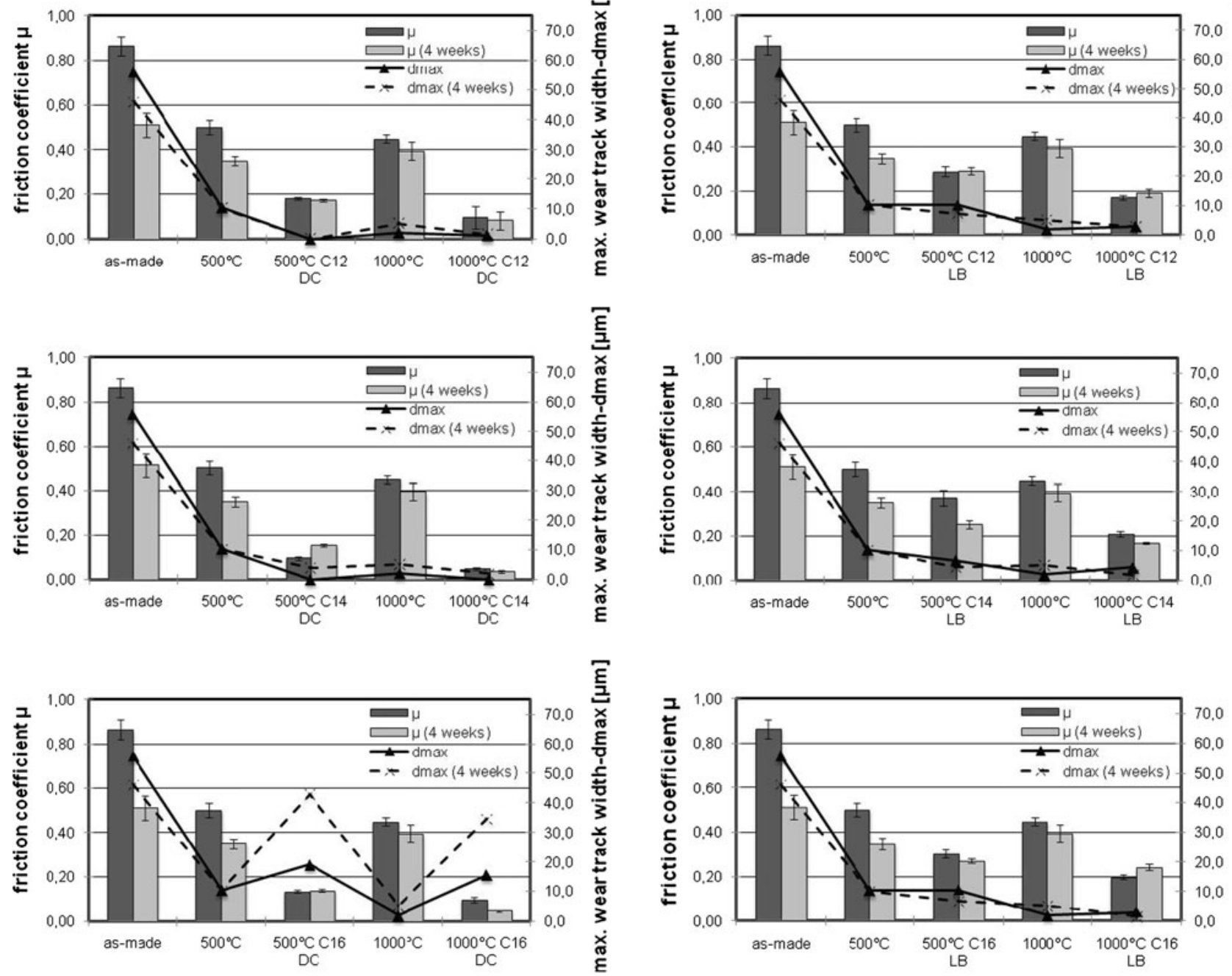

Fig. 5 The effect of the annealing temperatures of titania substrates on its frictional properties

The average value of the component $\gamma_{\mathrm{s}}^{\mathrm{LW}}$ for $\mathrm{C}_{12} \mathrm{HDDP}$ for all deposition methods is 5.1 times larger than the average component $\gamma_{\mathrm{s}}^{\mathrm{AB}}$, and even 9.6 times larger for $\mathrm{C}_{16} \mathrm{HDDP}$. A bigger contribution of the $\gamma_{\mathrm{s}}^{\mathrm{LW}}$ to the surface free energy is caused by a longer alkyl chain in HDDP.

Considering the dependence of surface free energies on the modification method it was observed that values of surface free energies for layers deposited, using the DC method are on average the same and around 57\% lower than for initial substrates. However, for a $\mathrm{C}_{14} \mathrm{HDDP}$ film deposited on rutile an increase of the surface free energy was observed, as compared to the initial substrate, of about $34 \%$. This sample has also a high rms roughness $(4.28 \mathrm{~nm})$ and differences in height between neighboring asperities reach $15 \mathrm{~nm}$.

In general, the surface free energies may be arranged in the following order: DC $<$ LB. Average values of the surface free energy for all deposited HDDP films is 33.7 and $42.4 \mathrm{~mJ} \mathrm{~m}^{-2}$ for DC (excluding $\mathrm{C}_{14} \mathrm{HDDP}$ on rutile), and LB methods, respectively. These differences result from various thicknesses of deposited films. Thick DC layers have low values of surface free energies, while in the case of thin layers (monolayers) obtained using LB method higher values were found.

\subsection{Frictional and Wear Measurements}

The results of frictional and wear measurements are presented in the form of bar graphs and solid/dashed lines. Each bar corresponds to the coefficient of friction $(\mathrm{CoF})$ value, however, the dark bar corresponds to the measurement of a fresh sample (one day sample) while the light bar corresponds to the measurement of exactly the same sample after 4 weeks. On the same graphs solid/dashed lines correspond to the maximum wear track width which corresponds to "fresh"/"4 weeks" samples, respectively. 

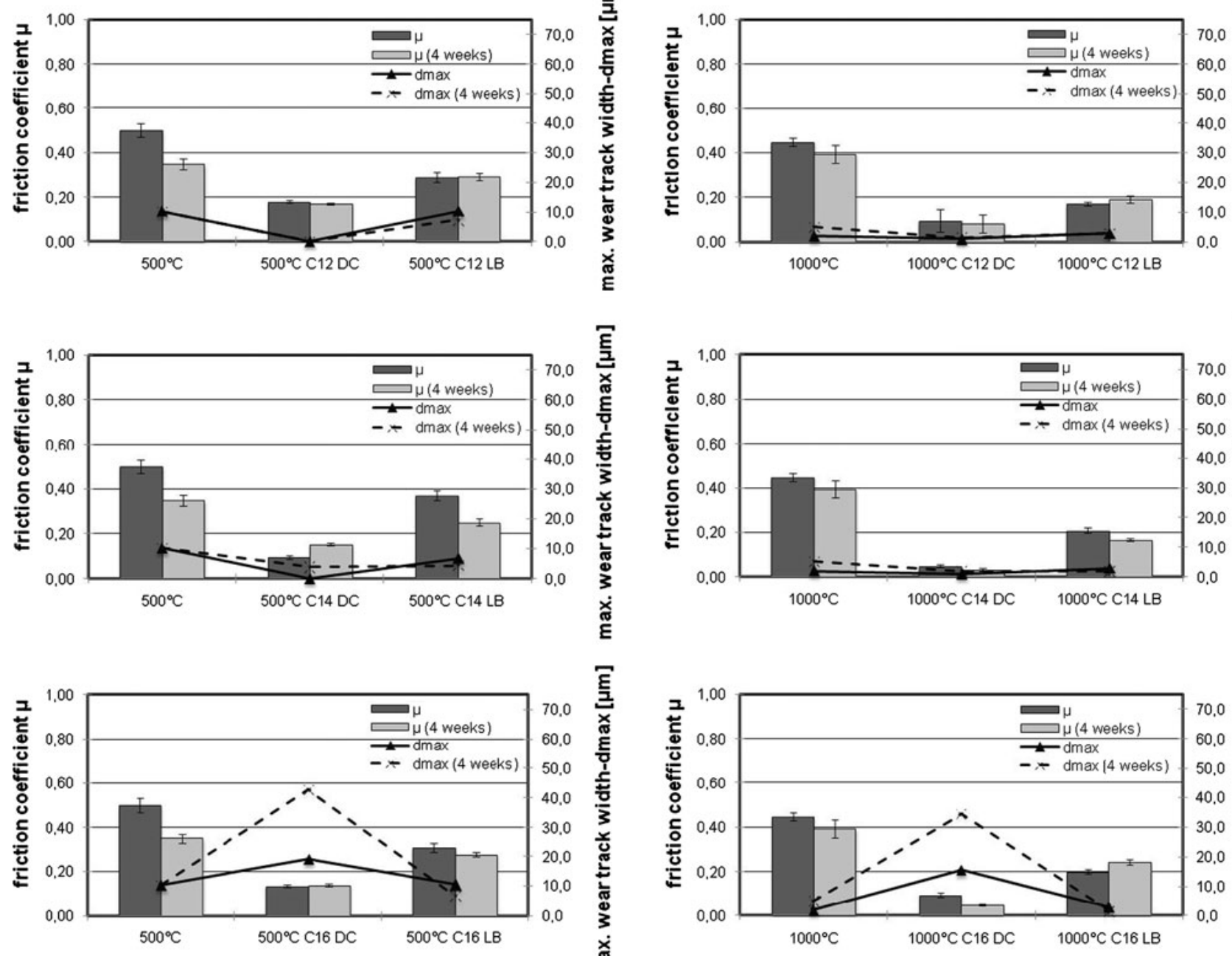

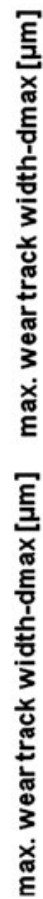

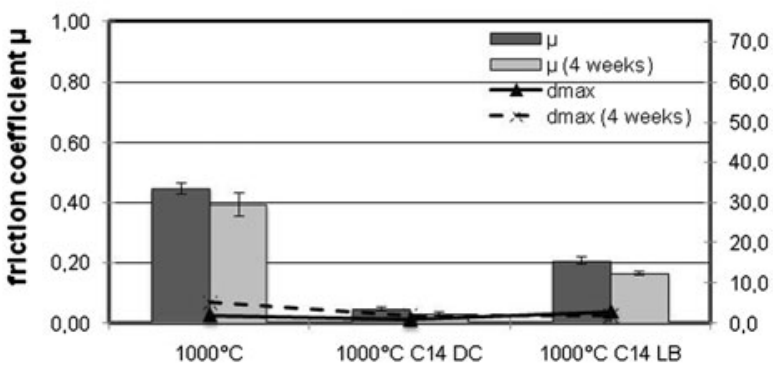

Fig. 6 The effect of the modification's method on frictional properties of titania layers

Each $\mathrm{CoF}$ value is an average value of at least three independent measurements. Coefficients of friction of titania before and after modification and maximum wear tracks after frictional tests are summarized in Table 2.

\subsubsection{The Effect of Alkyl Chains of HDDP}

The effect of the alkyl chains length of HDDP on frictional properties for the same deposition method and the same type of the substrate are presented in Fig. 4. Similar to the case of ZDDP films, considerable lowering of friction and wear is observed for all modified samples independent of the deposition method and the substrate. Other samples exhibit a rather random distribution of friction coefficient values and no trends can be found. It should also be noted that most of modified samples exhibit lower surface free energies and larger hydrophobicity than initial substrates which may contribute to the lowering of $\mathrm{CoF}$. As far as wear is concerned, modified titania coatings exhibit similar properties as substrate. No correlation of antiwear properties with the alkyl chain length was observed. Unusually high wear was recorded for $\mathrm{C}_{16}$ HDDPs deposited using DC method on all types of applied titania substrates. Such an effect may be attributed to the relatively large thickness of $\mathrm{C}_{16} \mathrm{HDDP}$ film. Under frictional conditions this film is worn out from the substrate surface which is observed as a wear trace.

\subsubsection{The Influence of the Annealing Temperature on Friction}

The influence of the annealing temperature of the titania substrate on the $\mathrm{CoF}$ and the wear is presented in Fig. 5. The effect of the annealing temperature is easily visible. Between titania substrates the lowest $\mathrm{CoF}$ and wear is exhibited by samples annealed at 500 and $1,000{ }^{\circ} \mathrm{C}$, which 

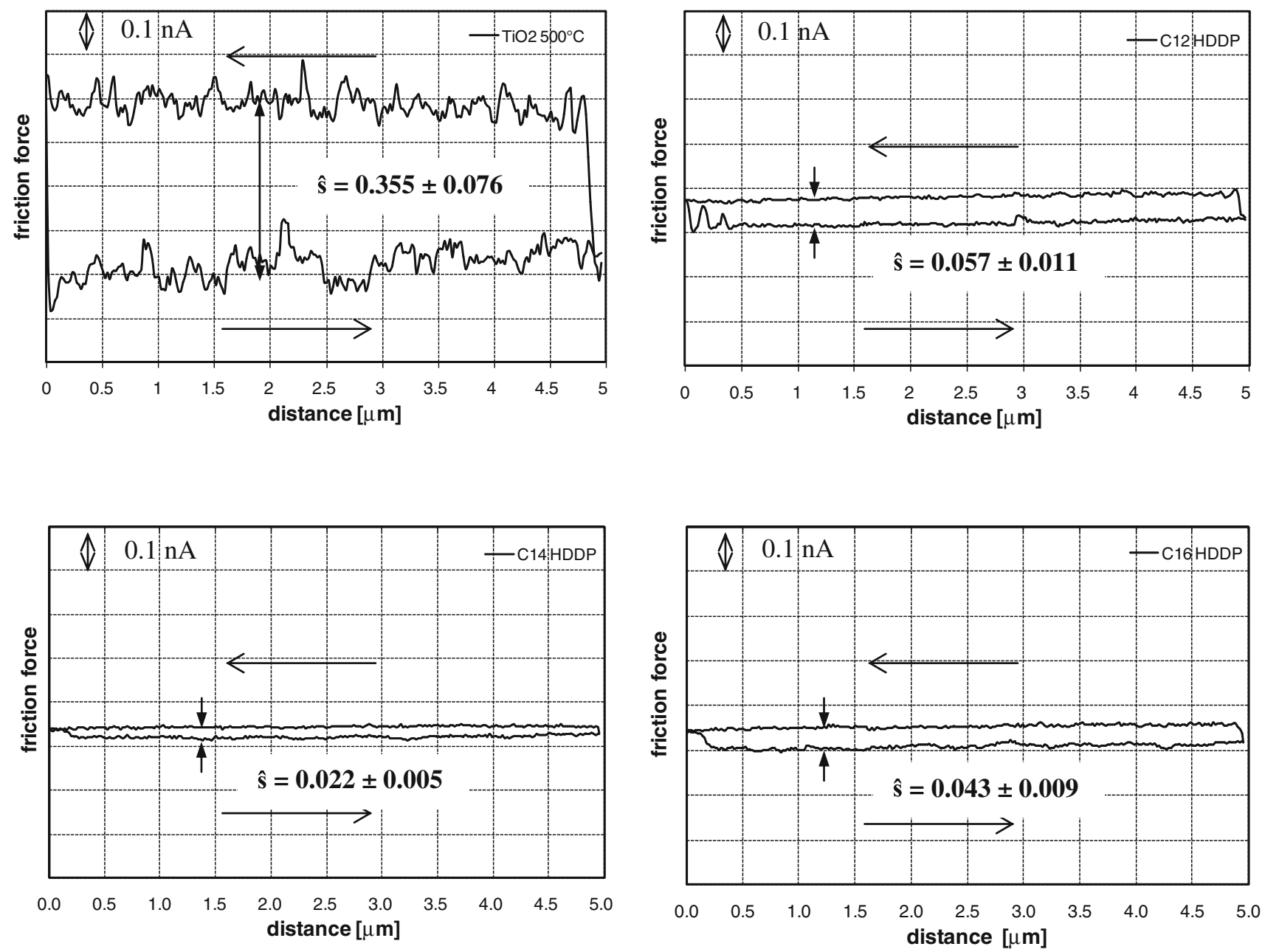

Fig. 7 Friction loops of $\mathrm{C}_{12}, \mathrm{C}_{14}$, and $\mathrm{C}_{16}$ HDDP deposited by DC method on $\mathrm{TiO}_{2}$ annealed at $500{ }^{\circ} \mathrm{C}$

is attributed to the presence of crystalline forms of titania: anatase and rutile. It is known from databases that these forms of titania are much harder than amorphous titania coatings (VHN $=894-974$ and VHN $=616-698$ for rutile and anatase, respectively). It is easy to notice that rutile is harder than anatase, which is also observable during frictional tests, where samples annealed at $1,000{ }^{\circ} \mathrm{C}$ (rutile) exhibit slightly better tribological performance than samples heated at $500{ }^{\circ} \mathrm{C}$ (anatase). In the case of modified samples, the annealing of substrates at high temperatures has a minor effect on the CoF and wear. The best tribological performance was recorded for the sample $\mathrm{C}_{14} \mathrm{HDDP}$ DC on $1,000{ }^{\circ} \mathrm{C}$ TDS. On the other hand relatively low reductions of $\mathrm{CoF}$ are exhibited by HDDP films deposited by the LB method, which achieve low level of $\mathrm{CoF}$ but only four weeks after sample preparation. It is also evident that, in the case of LB deposition, the temperature of the substrate annealing has a more pronounced effect as compared to modification because of the thickness of HDDP monolayers.

\subsubsection{The Effect of the Modification Method}

The effect of the modification method on the frictional properties of titania coatings is presented in Fig. 6. Here again, both methods are effective in reducing friction and wear. Good friction and wear reduction was observed for LB deposited HDDP films especially on "freshly" prepared TDS annealed at $100{ }^{\circ} \mathrm{C}$ (as-made). Notwithstanding that these films were deposited as monolayers, the effect of friction and wear lowering is observable at the macroscale. The best performance is exhibited by HDDP films deposited using DC method.

\subsection{AFM Friction and Wear Measurements}

AFM friction measurements were performed in contact mode. Scratch tests were performed only on samples deposited using DC method.

Figures 7 and 8 present AFM frictional loops. Each loop consists of two branches which represent two chosen force 

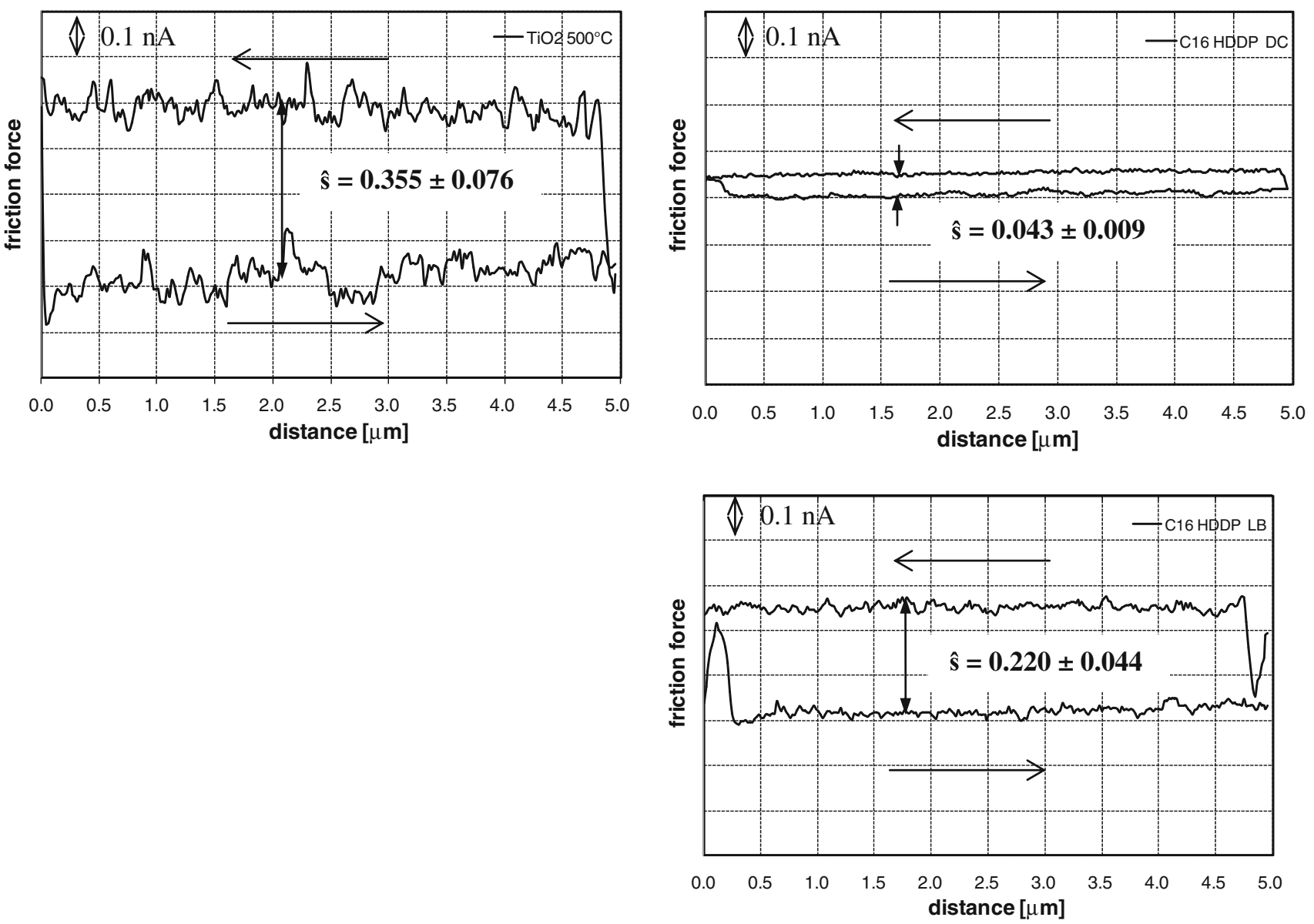

Fig. 8 Friction loops of $\mathrm{C}_{16} \mathrm{HDDP}$ deposited by DC and $\mathrm{LB}$ methods on $\mathrm{TiO}_{2}$ annealed at $500{ }^{\circ} \mathrm{C}$

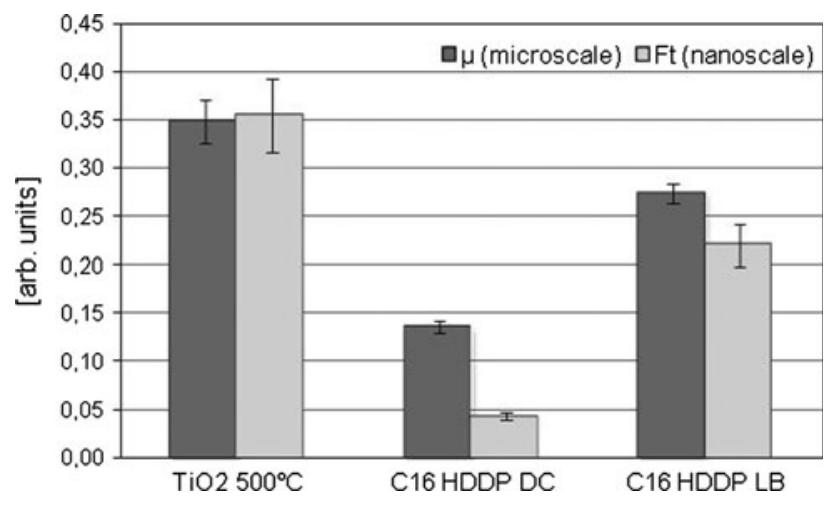

Fig. 9 Comparison of frictional test in micro- and nanoscale for $\mathrm{C}_{16}$ HDDP deposited by DC and LB methods on $\mathrm{TiO}_{2}$ annealed at $500{ }^{\circ} \mathrm{C}$

signals corresponding to lateral movement of the cantilever during scanning. Scan width was set to $5 \mu \mathrm{m}$. For each investigated film, the friction force is proportional to the difference between left-right and right-left scan. All graphs use the same units. It was found that TDS annealed at $500{ }^{\circ} \mathrm{C}$ exhibits much higher friction than HDDPmodified TDS $500{ }^{\circ} \mathrm{C}$ having different alkyl chain lengths deposited by DC method (Fig. 7). Although, there are minor differences in frictional forces between HDDPsmodified surfaces having various alkyl chain lengths, these frictional forces increase in the following order: $\mathrm{C}_{14}<\mathrm{C}_{16}<\mathrm{C}_{12}$. As far as the deposition method is concerned, for TDS $500{ }^{\circ} \mathrm{C}$ modified by $\mathrm{C}_{16} \mathrm{HDDP}$ the highest friction was recorded again for an unmodified substrate, while the dependence of frictional forces on deposition methods may be ordered as DC $<$ LB (Fig. 8).

Results of frictional tests performed using AFM were compared with data obtained in microscale tests using microtribometer (Fig. 9). Good correlation of measurements performed in two different scales was found. This correlation is visible for $\mathrm{C}_{16} \mathrm{HDDP}$ deposited on TDS $500{ }^{\circ} \mathrm{C}$ using various deposition methods, but also is valid for HDDPs having $\mathrm{C}_{12}, \mathrm{C}_{14}$, and $\mathrm{C}_{16}$ alkyl chain deposited using DC method (graph not shown).

From the reported investigations it is hard to establish the exact mechanism for the observed frictional results. Friction is a rather complex and depends not only on the type of the material, load, sliding speed, measurement conditions but also on the scale, environment, and many other factors. 
Results presented above clearly demonstrate that the state of the surface strongly influences its frictional properties. In our experiments we measured the surface topography, surface free energy and frictional properties of the coating. It appears that the key factor governing the observed frictional behavior is adhesion. Since experiments were carried out at low sliding velocities under technical dry friction conditions, the adhesive interactions more strongly influence the tribosystem than other effects.

Upon modification, the adhesive forces are lower due to the separation of the two ceramic bodies by a thin organic layer. Interactions between the molecules forming the organic interlayers are lower than in solids. Thus, the energy required to move modified surfaces are much smaller than the energy required to move two contacting ceramic surfaces. Changes in energy required to move two bodies are observed as lowering of the coefficient of friction. It is also clear, that the thickness of the organic interlayer positively influences friction. Lowering of the coefficient of friction for thick DC layers is more effective than in the case of thin LB layers. The thickness of organic layers is known from AFM measurements.

Upon modification the lowering of the surface free energy is observed, which can also indicate an adhesive origin of observed changes in friction. The correlation between the lowering of the surface free energy and the coefficient of friction was found, where a drop in surface free energy correlates with a decrease in the coefficient of fiction. However, it is difficult to establish these correlations between individual types of modifiers having various length of the alkyl chain.

It was found that, for unmodified coatings, the annealing temperature had large influence on the observed friction and wear, which is related to the changes in hardness of the coating due to the phase change. In the case of unmodified coatings, besides the adhesive component, also the effect of plastic deformation influences frictional results (e.g., larger wear of the anatase $\left(500{ }^{\circ} \mathrm{C}\right)$ coating). It is also probable from our other experiments, that the coatings annealed at $1,000{ }^{\circ} \mathrm{C}$ exhibit adhesive-diffusion character as compared to purely adhesive coatings prepared at $500{ }^{\circ} \mathrm{C}$. The adhesive-diffusion type of coatings exhibit better resistance to wear than adhesive ones.

\section{Conclusions}

In this study the influence of following parameters: deposition method (DC and LB), alkyl chain length of HDDP $\left(\mathrm{C}_{12}, \mathrm{C}_{14}, \mathrm{C}_{16}\right)$, and the type of the substrate (amorphous titania, anatase, and rutile) on tribological performance of titania coatings were investigated.
Modification of titania coatings by HDDP acids significantly enhances their tribological properties. Results obtained in this study are comparable to previously published results concerning ZDDP salts. Values of $\mathrm{CoF}$ and wear are comparable or even less for HDDP than for ZDDP which is related to longer alkyl chains $\left(\mathrm{C}_{12}, \mathrm{C}_{14}, \mathrm{C}_{16}\right)$ in acid molecules than in ZDDP molecules $\left(\mathrm{C}_{4}, \mathrm{C}_{12}\right)$. However, no significant changes in $\mathrm{CoF}$ were recorded between acids derivatives having various alkyl chain lengths. Larger differences are visible between applied deposition methods of HDDP. The best results were obtained for DC deposition while LB deposition was not so effective in lowering of friction. The temperature of the substrate annealing has significant influence on the tribological performance of the whole system because of the formation of crystalline forms of titania.

Lowering of the surface free energy and increasing of surface hydrophobicity was observed upon modification. The drop of the frictional forces on modified surfaces can be also attributed to the changes in surface free energy.

Analysis of the AFM surface topography provided information about the morphology of the prepared films. It was found, on the basis of AFM surface imaging, that HDDP acids may create various structures from homogenous and compact to island-like hierarchical structures depending on the type of modifier and deposition method. Good correlation between frictional measurements performed at micro-(microtribometer) and nano-scale (AFM) was found.

It was confirmed that similarly like in case of the application of ZDDP salts, successful modification of titania by HDDP films enable preparation of ceramic/ organic titania coatings having good antifrictional and antiwear properties. It was also proved that in technical dry friction conditions HDDP acids are as effective in enhancing the tribological performance on titania coatings as ZDDP salts.

Open Access This article is distributed under the terms of the Creative Commons Attribution Noncommercial License which permits any noncommercial use, distribution, and reproduction in any medium, provided the original author(s) and source are credited.

\section{References}

1. Spikes, H.: The history and mechanisms of ZDDP. Tribol. Lett. 17, 469-489 (2004)

2. Nicholls, M.A., Do, T., Norton, P.R., Kasrai, M., Bancroft, G.M.: Review of the lubrication of metallic surfaces by zinc dialkyldithiophosphates. Tribol. Int. 38, 15-39 (2005)

3. Barnes, A.M., Bartle, K.D., Thribon, V.R.A.: A review of zinc dialkyldithiophosphates (ZDDPS): characterization and role in the lubricating oil. Tribol. Int. 34, 389-395 (2001)

4. Graham, J.F., McCague, C., Norton, P.R.: Topography and nanomechanical properties of tribochemical films derived from 
zinc dialkyl and diaryl dithiophosphates. Tribol. Lett. 6, 149-157 (1999)

5. Smith, G.C., Bell, J.C.: Multi-technique surface analytical studies of automotive anti-wear films. Appl. Surf. Sci. 144-145, 222-227 (1999)

6. McFadden, Ch., Soto, C., Spencer, N.D.: Adsorption and surface chemistry in tribology. Tribol. Int. 30, 881-888 (1997)

7. Li, Y.-R., Pereira, G., Lachenwitzer, A., Kasrai, M., Norton, P.R.: $\mathrm{X}$-ray absorption spectroscopy and morphology study on antiwear films derived from ZDDP under different sliding frequencies. Tribol. Lett. 27, 245-253 (2007)

8. Ito, K., Martin, J.M., Minfray, C., Kato, K.: Low-friction tribofilm formed by the reaction of ZDDP on iron oxide. Tribol. Int. 39, 1538-1544 (2006)

9. Hsu, S.M.: Molecular basis of lubrication. Tribol. Int. 37, 553-559 (2004)

10. Chen, Y., Liu, W., Ye, Ch., Yu, L., Qi, S.: Preparation and characterization of self-assembled alkane phosphate monolayers on glass substrate coated with nano- $\mathrm{TiO}_{2}$ thin film. Mater. Res. Bull. 36, 2605-2612 (2001)

11. Hofer, R., Textor, M., Spencer, N.D.: Alkyl phosphate monolayers, self-assembled from aqueous solution onto metal oxide surfaces. Langmuir 17, 4014-4020 (2001)

12. Textor, M., Ruiz, L., Rossi, A., Feldman, K., Hähner, G., Spencer, N.D.: Structural chemistry of self-assembled monolayers of octadecylphosphoric acid on tantalum oxide surfaces. Langmuir 16, 3257-3271 (2000)

13. Brovelli, D., Hähner, G., Ruiz, L., Hofer, R., Kraus, G., Waldner, A., Schlösser, J., Oroszlan, P., Ehrat, M., Spencer, N.D.: Highly oriented, self-assembled alkane phosphate monolayers on tanta$\operatorname{lum}(\mathrm{V})$ oxide surfaces. Langmuir 15, 4324-4327 (1999)

14. Marguerettaz, X., Fitzmaurice, D.: Structures of monolayers of long-chain aliphatic acids deposited on metal, conducting glass, and nanocrystalline semiconductor substrates using LangmuirBlodgett techniques. Langmuir 13, 6769-6779 (1997)

15. Travers, E., Gnappi, G., Montenero, A., Gusmano, G.: Ceramic thin films by sol-gel processing as novel materials for integrated sensor. Sensor. Actuat. B-Chem. 31, 59-70 (1996)

16. Yusuf, M.M., Imai, H., Hirashima, H.: Preparation of mesoporous $\mathrm{TiO}_{2}$ thin films by surfactant templating. J. Non-Cryst. Solids. 285, 90-95 (2001)

17. Yamaguchi, E.S., Ryason, P.R., Labrador, E.Q.: Inelastic electron tunneling spectra of neutral and basic zinc dithiophosphates on native aluminum oxide surfaces. Tribol. T. 38, 243-252 (1995)

18. Gallopoulos, N.E., Murphy, C.K.: Interactions between a zinc dialkyl phosphorodithioate and lubricating oil dispersants. ASLE Transactions 14, 1-7 (1971)

19. Piwoński, I.: Preparation method and some tribological properties of porous titanium dioxide layers. Thin Solid Films 515, 3499-3506 (2007)

20. Piwoński, I., Ilik, A.: Vapor phase modification of sol-gel derived titania $\left(\mathrm{TiO}_{2}\right)$ surfaces. Appl. Surf. Sci. 253, 2835-2840 (2006)

21. Van Oss, C.J., Good, R.J., Chaudhury, M.K.: Additive and nonadditive surface tension components and the interpretation of contact angles. Langmuir 4, 884-891 (1988)

22. Onoe, H., Matsumoto, K., Shimoyama, I.: Three-dimensional micro-self-assembly using hydrophobic interaction controlled by self-assembled monolayers. J. Microelectromech. Syst. 13, 603-611 (2004)

23. Yamaguchi, E.S., Primer, R.L., Aragón, S.R., Labrador, E.Q.: Dynamic light scattering studies of neutral diisobutyl zinc dithiophosphate. Tribology Trans 40, 330-338 (1997)

24. Martin, P., Szablewski, M.: Tensiometers and LangmuirBlodgett troughs operating manual NIMA Technology, 5th edn. (1999) 